\title{
THE INTERPLAY BETWEEN EARTHEN LANDSCAPE HERITAGE AND SOCIO- POLITICAL DEVELOPMENTS IN THE NORTHERN WEI DYNASTY: A VIEW FROM ARCHAEOLOGY
}

\author{
Yi Zhao, Chaoran Xu
}

Tianjin University - School of Architecture, Tianjin, China

KEY WORDS: Earthen Landscape Heritage, Landscape Architecture, Northern Wei Dynasty, Archaeological Data.

\begin{abstract}
:
In the past two decades, landscape archaeology has undergone a paradigm shift from traditional theoretical methods to being practically oriented, with the advent of the widespread application of philosophical theories (such as phenomenology, hermeneutics, and others) and the emerging new technologies in social sciences. Nevertheless, landscape archaeology has not been able to garner the attention it requires from Chinese archaeology, which fails to understand its significance behind the systematic regional survey methods. Rather, for a long time, the study of the man-land relationship has been considered to be a part of environmental archaeology. Besides, the landscape elements in archaeological excavations were often considered as mechanical interactions between people and the environment, resulting in a lack of holistic and systematic research on a selection of archaeological sites. The focus however has remained restricted to the earthen remains and relics in the archaeological process. The Northern Wei Dynasty was the first nomadic regime to control the Central Plains in the Chinese history and moved its capital three times for the purpose of sinicization. The recent archaeological excavations of the ancient city of Shengle, imperial palaces, tombs, sacrificial sites, gardens, Yinshan palaces, and the border defense facilities during the Shengle period of the Northern Wei Dynasty have revealed several phenomena and evidence of the cultural integration of the various ethnic groups. As mentioned earlier, the limitations in the research horizon have led to the in-depth analysis and research of archaeological relics and archaeological data during this period seeking the desired attention. This study considers landscape archaeology, anthropology, sociology, and history as the primary research methods pertinent to the above situation. It considers archaeological relics and archaeological data from the prosperous period as the research object and thoroughly analyses the relationship between the people and the earthen landscape relics, to reveal the social culture, the religious beliefs, the politics, and the military behind the integration of the multi-ethnic culture, along with the cognition of the natural environments, the social structures, and the religious spaces. Simultaneously, the analysis results would also endeavor to integrate the artifacts, the relics (space, structure, layout, and locational relationship), road grids, surrounding environment, and several other surface space elements to restore and reproduce the prosperous social and cultural situations scenes of the bygone period. The final outcome shall become a typical research case. By comparing and combing the archaeological discoveries of the Northern and the Southern Dynasties of China and the pertinent archaeological data, we could further understand and explain the multi-ethnic cultural development and evolution while providing an essential theoretical basis for the present social and cultural research on the Northern Wei Dynasty in China.
\end{abstract}

\section{INTRODUTION}

\subsection{An overview of the sites of the Northern Wei Dynasty}

The Northern Wei Dynasty (ca 386-534/535 CE) might be called one of the most turbulent periods in Chinese history. This period (ca 220-589 CE) encompasses the rule of the Wei, Jin, and Southern and Northern Dynasties. These regimes also represent the rule of an ethnic minority, the Xianbei. There were three capital cities during this period: Shengle 盛乐 (ca 386-398 CE), Pingcheng 平城 (ca 398-493 CE), and Luoyang 洛阳 (ca 493534 CE) - all in northern China (Nirunan, 2009). Archaeological remains from this period, such as Buddhist art, poetry, and literature, and certain architectural styles, show a remarkable integration of nomadic culture and Central Plains culture. Previous archaeological studies have analysed the social structure, architecture, and urban planning of the period by assessing the architectural form and layout of these capital cities. However, the latest archaeological excavation, conducted by the Inner Mongolia Institute of Cultural Relics and Archaeology in October 2020, found that there were strong links between the continued influence of development of Central Asian culture. As a northern nomad from the Daqing Mountains 大青山, the Xianbei 鲜卑族 took the initiative to learn from the Central
Plains culture in moving south. The Northern Wei Dynasty also became the first feudal dynasty established by northern nomads in Chinese history to unify the Yellow River Basin, also, inherited and continued the traditional sacrificial rites of the Central Plains Dynasty. Although their nature worships began to resemble those of people living in the Central Plains, it still retained features of nomadic beliefs. Furthermore, the beliefs and other sociological factors in Landscape Architecture were inseparable from the establishment of military defences such as the Northern Wei's great wall.

However, there are still some problems that need to be solved as soon as possible, first of all, the preservation of the site is not ideal. The site's original plan was square, and its shape has been seriously damaged due to the nearby villagers' cultivated land. Archaeologists only worked here for four to five months a year. They could only covered it with plastic sheets when they cannot do archaeological work. Secondly, the on-site excavation records and data generation are far from enough. Professional interdisciplinary research need to seek to understand the nature of the site, and put forward suggestions for developing follow-up protection strategies about the site. The proposed work seeks to conclude the landscape forms under the influence of the sociological factors using archaeological data. 


\subsection{Literature review}

Zhanghai (2010) stated that landscape archaeology is a comprehensive regional research method based on the study of surface spatial structures, which focuses on human spatial cognition and social practice activities(Inomata et al. ,2020). Knapp and Ashmore(1999) believed that sociological research in landscape archaeology mainly focuses on four aspects: cultural memory, social identity, social order, and social transformation. As such, in order to analyse the Yuanqiu 圆丘 site, the landscape structure and ground remains of the site must be examined and the relationship between the site and the internal and external environment(Arıkan et al. ,2020) should be determined to analyse the internal relationship between landscape sociology and environmental construction. First, this study analysed the internal relationship of the landscape of the Yuanqiu site, the Yinshan Mountains, and the border defences of the six towns from a macroscopic perspective. At the micro level, this study focused on the construction characteristics of the Yuanqiu site itself and combined the two to analyse its deep cultural core.

\section{RESEARCH METHODS}

This work analysed the social structures and hierarchies of different groups of people and consider their cultural differences to be the catalyst in their respective ways of settling the landscape(Figure1).

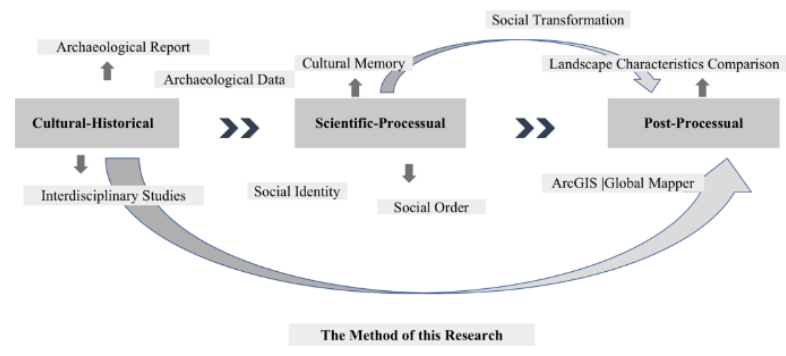

Figure 1. Depiction of research methods.

\subsection{The cultural-historical stage}

The early stage of the study analysed the relevant historical documents, archaeological excavation reports, and the landscape itself to explore the character of the site in a preliminary manner, used landscape archaeology methods because they emphasise people's perceptions and experiences (Knapp and Ashmore, 1999).

\subsection{The scientific and processual stage}

The middle of the study reconstructed the historical development of the site with the use of archaeological investigations of settlement patterns(Chen Shengqian, 2019), analyses of watersheds, and analyses of the historical ecosystem. These investigations required fieldwork undertaken in cooperation with local archaeology research institutes. This study used ArcGIS, Global Mapper, Loca Space Viewer, and DEM (Digital Elevation Model) to comprehensively analysed the elevation, slope, and plant coverage of the site. The excavation reports which these investigations produce - along with data from unearthed tombs, animal remains, ceramics, utensils, and cereals - were analysed in order to develop a more complete picture of how the site developed.

\subsection{The post-processual stage}

Finally, though combining the historical data with the site's current situation, using remote sensing and other image information to analyse comprehensively, this study defined and summarised the characteristics, meanings, and historical importance of the site.

\section{THE HERITAGES UNDER THE POLITICS}

\subsection{Sacrifices and Construction of the Northern Wei Dynasty}

The round mound (Yuanqiu) at the top of onggon dabaga (Figure 2 and Figure 3) has been C14 dated to ca. 430-490 CE. The site and the artefacts found there have been studied by scholars from the Institute of Cultural Relics and Archaeology of Inner Mongolia since the 1950s. They have suggested that the site was a military outpost of Wuchuan Town (Zhangyu, 1958); that it was in fact an Ajitou Hall, which was the palace of the Wei emperor (Wangyuping, 1984); that it was the beacon tower of Baidao city (Suzhe,1995); that the site was part of the Great Wall of the Han Dynasty (Chenyongzhi et al. ,2006); and that the site was attached to the Ajitou Hall in the ancient city of Tuliang Cheng (Yuanyongchun and Zhangwenping, 2015). In addition to speculating on its various functions and origins, scholars have determined that ritual sacrifices were performed at the mound through their analyses of things such as the wooden pillars of the building, building materials, the dilapidated walls of Wei Lei 墤 埒, pottery pieces, stoneware, ironware, residual bricks, and livestock remains found at the site.

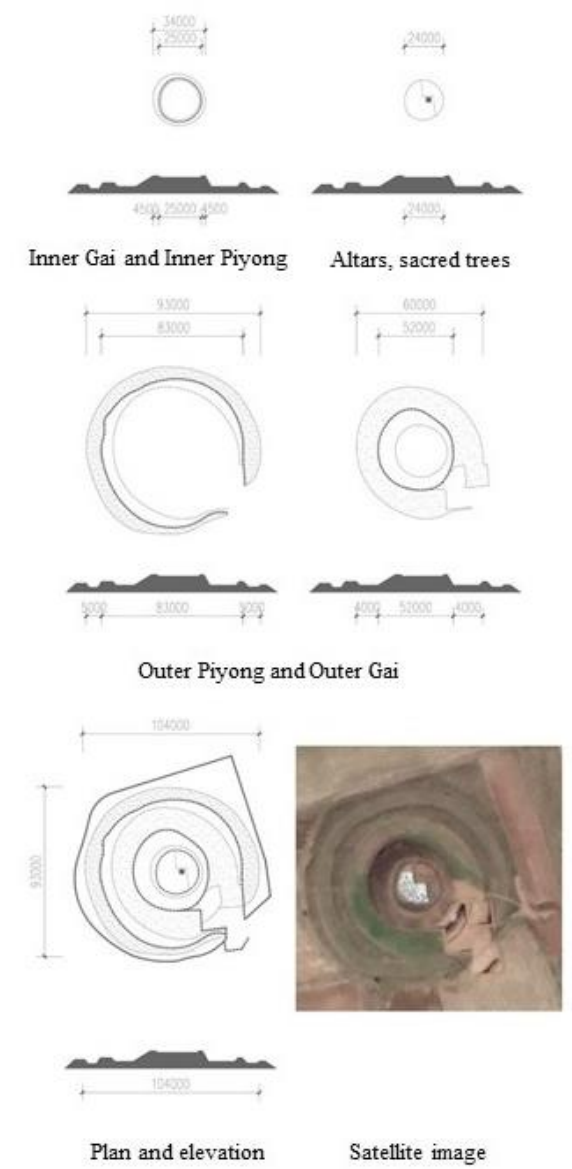

Figure 2. Plan, elevation, and building structure of the Round Mound at the site. 


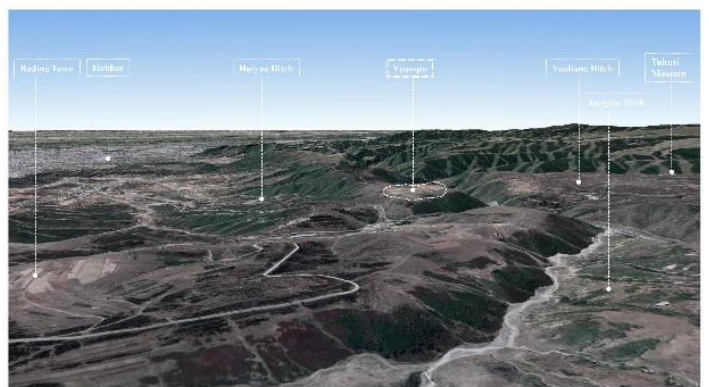

Figure 3. An analysis of the line of sight to the south

Throughout the history of gardens and architecture in the Northern Wei Dynasty, the concepts of harmony between man and nature and worship of the gods can be found during the construction process. In the early days of the founding of the Northern Wei Dynasty, Emperor Tuobagui won the Northern War and opened up and expanded the territory; however, he neglected customs of sacrifice. Emperor Xiaowen, whose ancestor was the great Emperor Tuobahong, adopted the experience of the former dynasty and the culture of the Central Plains and integrated the characteristics of the Northern Wei Dynasty. A new ceremony was established and sacrificial rites became a system. After the capital was moved to Luoyang, Emperor Tuobaque immersed himself in metaphysics and the sacrificial ritual system gradually declined. In 418, there were 324 places dedicated to the gods of mountains, rivers, and oceans. At that time, Pingcheng Palace, the capital of the Northern Wei Dynasty, was used to pray for good weather and harvest. The Six Gods, Lingxing 灵星, Fengbo 风伯, Yushi 雨师, Siming 司命, and Silu 司禄 and Xiannong 先农 set up altars for sacrifices there. In 472, there were more than 1,200 places where sacrifices to the gods were made. In addition, sacrifices were affected by astrological and celestial phenomena. Empress Liu built temples and shrines based on the results of comet divination. The Book of Wei(Weishou,554) states, "In the early days of Taizu(Tuoba Gui), there were two comets to see, and Empress Liu used diviners to practise divination about the two stars. She said, 'If you offer sacrifices to gods or ancestors, you will rule all the land.' After that, she set up her sacrifice system."'

Therefore, in the Pingcheng era, due to the construction of Yuanqiu, Fangze 方泽, Sijiao 四郊, Taimiao 太庙, Taishe 太社, Fangtan 方坛, and Mingtang 明堂 in the capital and outside the city, the national sacrificial system of the Northern Wei Dynasty was important to cities, palaces, palaces, and temples. The development and construction of rural landscapes played a significant role in promoting. There were several concrete manifestations of this. In terms of urban construction, the layout of the inner city, Pingcheng, was adjusted due to the construction of Mingtang, Taimiao, Nanyuan 南苑 and Xiyuan 西苑 worshipped the stars and prayed for rain. In the next year, Emperor Xiaowen also prayed for blessings and stars in Beiyuan 北苑. In 486, Emperor Xiaowen ordered Minister Li Chong to preside over the construction of Mingtang. In addition, the emperors of the Northern Wei Dynasty often set up and lived in temporary palaces and offered sacrifices(Zhangwenping, Yuanyongchun, 2015). In the construction of temple gardens, countless temples were built to worship the gods of the heavens, stars, wind, rain, and lightning. After the completion of the Deer Garden 鹿苑 of the Royal Palace Garden, Leigong Mountain, Fang Mountain, Bai Mountain, and the valley in the northern part of Pingcheng formed a complex of courtyards, halls, Buddhist temples, and grottoes (Xuezheyi, 2016) . The selection of sites in the western and northern suburbs, Yuanqiu, and Fangze on the city walls inevitably promoted the development of suburban landscapes. In each month of the year, the royal family held rituals in various places. For instance, Tuobagui established a series of sacrificial rituals in 398, and ceremonies were held every month(Table 1 ).

\begin{tabular}{|l|l|}
\hline \multicolumn{1}{|c|}{ Site } & \multicolumn{1}{|c|}{ Etiquette } \\
\hline Yuanqiu & $\begin{array}{l}\text { Sacrifice to heaven, sacrifice } \\
\text { with fire }\end{array}$ \\
\hline Southern suburbs & $\begin{array}{l}\text { Sacrifice to heaven, pray for a } \\
\text { good harvest }\end{array}$ \\
\hline Altar of praying for Rain & Pray for rain \\
\hline Mingtang & $\begin{array}{l}\text { Sacrifice to the Jade Emperor, } \\
\text { royal funeral, announce } \\
\text { political affairs }\end{array}$ \\
\hline Temple of Five Emperors & Sacrifice to the gods \\
\hline $\begin{array}{l}\text { Sun altar, Moon altar, Sun } \\
\text { and moon altar, Eastern } \\
\text { and Western Suburbs }\end{array}$ & Sacrifice to the sun and moon \\
\hline Stars altar & $\begin{array}{l}\text { Sacrifice to five stars and } \\
\text { twenty-eight stars }\end{array}$ \\
\hline $\begin{array}{l}\text { Altar of the god of wind } \\
\text { and rain }\end{array}$ & $\begin{array}{l}\text { Sacrifice to the god in charge of } \\
\text { storms and thunderstorms }\end{array}$ \\
\hline
\end{tabular}

Table 1. The main places and rituals of worship heaven in ancient times.

\subsection{Ruins, mountains and cities}

The onggon dabaga is located in the Daqing Mountains on National Nature Reserve in the middle of the Yinshan Mountains. As the dividing line between the Mongolian Plateau and the Central Plains, the Yinshan Mountains Range is known as the Imperial Frontier Site. During the Northern Wei Dynasty, the White Road was set up here as the most convenient main road in the Yinshan Mountains Range, and six towns in the Northern Wei Dynasty were set up to resist Gaoche 高车族. The invasion of northern tribes, such as the Rouran 柔然, formed a defensive line for the six-town frontier defence and the Great Wall of the Northern Wei Dynasty. The towns to the north of the Yinshan Mountains were the core of the frontier. The Wuchuan Town, for instance, had guard generals who were always valued by the emperors of the Northern Wei Dynasty. In addition, the Book of Wei records that Emperor Tuobatao visited Yinshan more than ten times from 424 to 449 , indicating the high political and military status of Yinshan. Tuobagui once set up an altar to sacrifice during his visit to Yinshan Mountains. 'Visiting the palace, each erected the altar, and sacrificed to Tailao 太牢. Every year, all the priests guard the sacrifice.' Archaeological findings indicated that the distance between the site and Ajitou Hall 阿计头殿 (now Tuchengliang Ancient City) of the Wei Emperor's Palace was only 4.5 kilometres. Yuan Yongchun and Zhang Wenping(2016) first proposed that the hill was an altar site attached to Ajitou Hall, which was confirmed by the Inner Mongolia Autonomous Region Cultural Relics Research Institute. Yuanqiu was located northwest of Shengle's ancient capital. Although it was far from Pingcheng and the new capital Luoyang, it was closely connected with Wuchuan Town and the southern line of the Great Wall of the Northern Wei Dynasty (Figure 4). The manner in which the six-town system of the Yinshan Mountains Range, including Ajitou Hall, Yuanqiu, Shengle, and Pingcheng, was interconnected and interlocked provided a relatively strong geographically formed defence ring and a connection between palaces. Yuanqiu became a symbol of the centralised rule of the Northern Wei Dynasty in Yinshan. This not only encouraged the morale of the frontier generals but also 
stabilised the position of the frontier aristocratic regime system and became the sustenance of the social groups and nomads who stayed behind the frontier.

\section{FEATURES OF YUANQIU}

\subsection{Site shape}

The shape of the ruins is similar to the Yuanqiu in the past dynasties, but the materials were slightly different. It was a round altar structure built with three layers (Figure 2), covering an area of approximately $7,620 \mathrm{~m}^{2}$. This was the highest round altar, equipped with sacred wood. Large-scale wooden building damage and carbonisation remains were found. In addition to the altar, inner and outer Piyong 辟雍 and inner and outer Gai 垓 were inside. Based on the surveying and mapping results and the archaeological excavation data released by the Institute of Cultural Relics and Archaeology of the Inner Mongolia Autonomous Region in 2020, the current plan and elevation of the centipede dam and hill site were drawn as Figure 1.

Shuowen: 'Three is the number of heaven, earth, and people.' Three represented the ancients' perception of the formation of the universe and the relationship between heaven, earth, and man. The Yuanqiu and Fangtan in the Northern Wei Dynasty also adopted three-tiered forms. The Yuanqiu in the Tuobagui period had four altars connected to the four princes, which were the three layers of low walls. Therefore, the form of three-tiered hills was generally recognised by the emperors of the Northern Wei Dynasty.

Shui Jing Zhu (Xingyu,2012) by Li Daoyuan of the Northern Wei Dynasty used a combination of compilation and creation, and used rivers as a classification basis to record different types of landscapes. The palace gardens of this dynasty included the Guangde Hall 广德殿, Ajitou Hall, and Yunzhong Palace 云中 宫. Beiyuan in Luo River and Hualin Garden and Xiyou Garden in Gu River fully explained the relationship between the river system and the geographical landscape and gardens. The geographical position of the ruins of Yuanqiu was superior, which could be described as mountain surrounded by river. Jiguanzi Mountain (1840m) was on the east side, Chaoshihao Mountain (1905m) was on the north side, and Jinluandian Mountain (1972m) was on the northeast side. On the west side, there were mountains such as Motianling $(1711 \mathrm{~m})$, with Erdao Ditch, Youliang Ditch, Huiyao Ditch, and other valleys surrounding it(Figure 3).

\subsection{The sight of the ruins landscape echoes the sky}

The elevation map(Figure 5)drawn by AcrGIS and Global Mapper revealed that the surrounding hills and peaks overlapped, the Yinshan Mountains stretched continuously, and the main peak of Daqing Mountain was as high as $2195 \mathrm{~m}$ above sea level. However, the top of the dam, where the hill was located, was relatively flat. This phenomenon may have been caused by the artificial levelling of the land during the initial construction, when the villagers ploughed land, or when land had an advantage. Although, there is no evidence to support this, it is certain that the sight of the site was empty and wide. Standing on the crest of the dam, current Hohhot urban area is clearly visible(Figure 6). The residual height of the inner wall was approximately $1-1.5 \mathrm{~m}$. When entering the hills, the line of sight was relatively closed. After stepping up the steps, the view became clear and the intention of dialogue with the sky could be expressed through a wide field of vision(Figure 6). The circular structure inside the hills facilitated the visual creation of an empty, solemn, and solemn atmosphere.
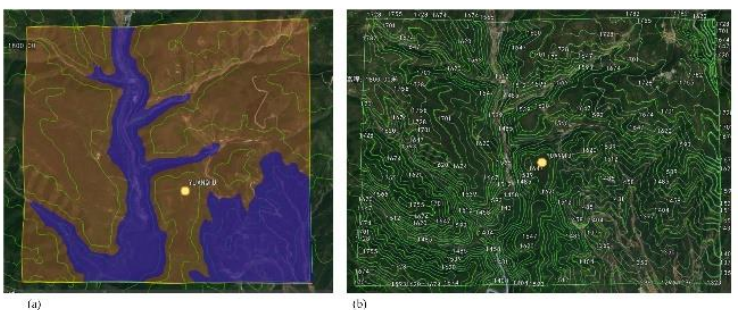

Figure 5. Earthwork(a) and contour analysis(b) .
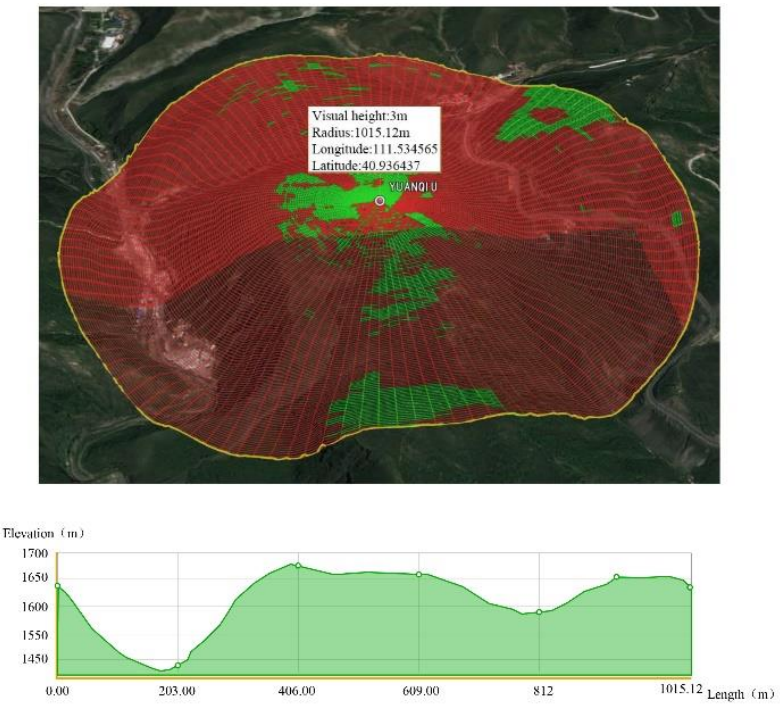

Figure 6.Visible area (invisible area in red) and elevation.

\section{LANDSCAPE FEATURES}

\subsection{The sacrificial landscape intertwined with the culture of the Central Plains and Xianbei}

Pingcheng of the Northern Wei Dynasty was the centre of world cultural exchanges at that time. Empress Feng abolished the study of witchcraft, respected Confucius, repaired rituals and music, rectified customs, revitalised schools, and vigorously promoted the Sinicization reform at all levels of society. As far as Emperor Xiaowen was concerned, although he followed the advice of the minister Wang Su to combine the suburbs and the hills, it was still slightly different from the hills in the Central Plains. First, the hills in the central plains used more stones. Masonry, the main body of the dam crest, was rammed with clay. The ancient city of Shengle, the side wall of Deer Garden and other Northern Wei palaces also had relics of rammed earth, which is in line with the natural original ecology of the royal gardens of the Northern Wei Dynasty and the grand pattern of real mountains and waters(Chengshengqian, 2019). Second, the circular altar form was designed to reflect the unity of nature and man, whether it was in the Central Plains or Inner Asia. However, the Yuanqiu was used to express the worship of the gods through the towering inner walls and excellent geographical location. Today, it means Earth-scape(Johnson,M.,2005).Third, offering sacrifices to the sky in the southern suburbs of the hills was the tradition of the Han Dynasty and the core link of the royal etiquette in the Central Plains. However, this existed in the palace, and the choice of location did not completely follow the social traditions of the Han Dynasty. Therefore, take Yuanqiu as an example could observed the penetration of the Central Plains culture into the early Northern Wei society. 


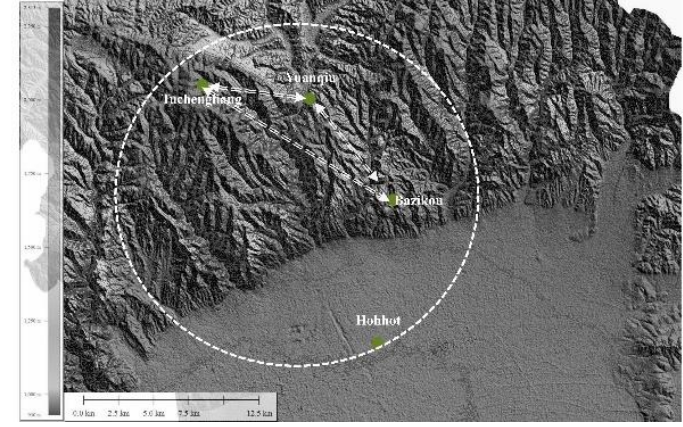

Figure 7.The relationship between Yuanqiu and surrounding towns.

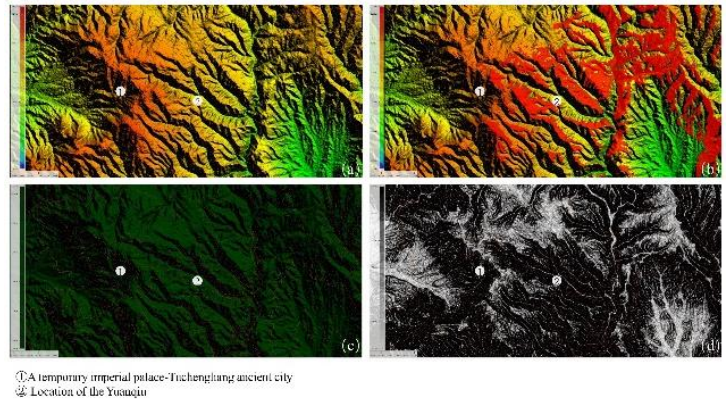

Figure 8. Landscape analysis map.

(a) Elevation analysis chart (b) Visual field analysis chart

(c) Vegetation cover analysis chart (d) Slope analysis chart

\subsection{Frontier defence landscape due to the mountain-shaped water}

The ancients in China believed that offering sacrifices to mountain gods and river gods could bless production and life and bring clouds and rain, where high and famous mountains were symbols of specific social order and connected to the sky as a ladder, as well as Maya(Inomata et al.,2020). Academia generally believes that the Wei-Jin period was a turning point for Chinese gardens, and the aesthetics of the landscape reached their climax during this period. The anthropomorphic idea in landscapes occupies the mainstream, and the park pays attention to model mountains and water. The courtyard presents half hill and half gully, and the garden is in the general environment of the Wei, Jin, Southern, and Northern Dynasties. It presents the aesthetic and secluded relationship between mountains and rivers of comfortable in the hills(Figure 8). Therefore, the site of the Yuanqiu was located on the plateau, which not only used the mountains and rivers to present the characteristics of simple, rough, and grand gardens in the early Northern Wei Dynasty but also used the pattern of large mountains and rivers to add natural forests and high mountains to the landscape of other palaces, created a natural artistic conception.

\section{CONCLUSION}

This study reflected the intervention of national politics on border defences and sacrificial sites of the Northern Wei Dynasty. However, some omissions are inevitable in the excavation of documents alone. The dual evidence of archaeology and documents can infer the nature and age of its surface. Landscape archaeology can further reflect people's recognition of time and space and intuitive mapping of knowledge and understanding.

Landscape archaeology provides not only different perspectives for the investigation of the characteristics of a single site but also new ideas for the protection and research of large sites. In the present study, although only the Yuanqiu was the object, landscape archaeology explored the organic connection between the excavated sacrificial sites in the surrounding area, including the Yinshan Mountains in the large-scale area, the mesoscale, and the active connection between the capitals and border defence.

The concept of harmony between man and nature that has always been adhered to in the process of design, site selection, and use of the Yuanqiu has evolved into the basic concept of harmonious coexistence between man and nature, expressing the original romance of the landscape. The spirit of ideology, the spiritual core of the same line, could also provide guidance for the future construction of heritage parks.

\section{ACKNOWLEDGEMENTS}

This research is partly funded by the National Natural Science Foundation of China (No.513783334). The authors gratefully acknowledge the support from Dr Anke Hein of Oxford University, and Professor Charleux Isabelle of PSL University.

\section{REFERENCES}

Ni Runan, 2009. Archaeological studies from Tuoba to the Northern Wei Dynasty_ Focus on tombs. Peking University.

Zhang $\mathrm{Yu}, 1958$. Investigation of the ancient city sites of Eastern Han and Northern Wei after Daqingshan in Inner Mongolia. Archaelogy,03: 14-22

Wang Yuping, 1984. Cultural relics and historic sites related to "Baidao" in the north of Hohhot . Inner Mongolia Cultural Relics and Archaeology, 00:71-76+89.

Su Zhe, 1995. Northern Wei garrison relics in tumechuan and Daqing Mountains, Inner Mongolia. Research Center for Chinese traditional culture, Peking University. Ancient Chinese Literature Search.

Chenyongzhi ,Li Qiang ,Liu Gang.2006. Main achievements of archaeological excavation of Tuchengzi ancient city in Helingeer County. Inner Mongolia Cultural Relics and Archaeology,01:10-17+118-120.

Yuanyongchun, Zhangwenping, 2015. Preliminary study on the nature of Round Mound site on the crest of Daqing Mountains in Hohhot. Inner Mongolia Social Sciences, 036(005):76-80.

Zhanghai,2010. Landscape Archaeology: Theory, Method and Practice. Southern cultural relics, 004: 8-17.

Knapp, A.B.; Ashmore, W.1999. Archaeological landscapes: Constructed, conceptualized, ideational. In Archaeologies of Landscape: Contemporary Perspectives; Ashmore, W., Knapp, A.B., Eds.; Blackwell: Oxford, UK. pp. 1-30.

Arıkan, Bülent, Franziska Mohr, and Matthias Bürgi. 2020. Exploring the common ground of landscape ecology and landscape archaeology through a case study from eastern Anatolia, Turkey. Landscape Ecology.

Weishou, Book of Wei, 1974. Zhong Hua Book Company.

Zhangwenping, Yuanyongchun, 2015. Archaeological investigation confirms the former site of Guangde Hall of Yinshan palace in Northern Wei Dynasty. Grassland cultural relics, 01:131-134+139. 
Xuezheyi, 2016. Site Survey and Construction Technique Analysis of Northern Wei Dynasty Deer Park. Taiyuan University of Technology.

Xingyu,2012. The garden research of Shuijingzhu. Tianjin University.

Chen Shengqian, 2019. Paradigms and paradigm shift in China's archaeological research . Chinese Social Sciences, 182-203+208.

Johnson, M. 2005. Thinking about landscape. In Archaeology: The key concepts, ed. Colin Renfrew and Paul Bahn, page number. London, UK: Routledge.

Inomata, Takeshi, Daniela Triadan, Veronica A. Vázquez López, et al.,2020.Monumental architecture at Aguada Fénix and the rise of Maya civilization. Nature 582: 530-533. 